\title{
The Social Construction of Legal Norms
}

\author{
In Social Ontology, Normativity and Law, \\ eds. M. Garcia-Godinez, R. Mellin, R. Tuomela, \\ De Gruyter, 2020: pp. 179-208. \\ Kirk Ludwig \\ Philosophy Department \\ Indiana University, Bloomington
}

\section{Introduction}

What are legal norms? What is the nature and extent of the authority that they have over us? What sorts of reason do they give us for action? What is their relation to other sorts of norms, especially moral norms? ${ }^{1}$

A legal norm applies only within the jurisdiction of a legal system. Legal norms are thus relative to legal systems. We can speak of widespread or even universal legal norms, but what we have in mind are there being similar norms in many or all legal systems. Legal norms are therefore the result of reflective human social activity. There were no legal norms in the state of nature, in small tribes of hunters and gatherers. There were social norms of various sorts, and legal norms are a sort of social norm-as are the norms of etiquette-but the institutional structures for legal norms were not in place. Thus, legal norms are an invention.

In this paper, I want to say something about the kind of invention that they are and how they are similar to and different from other social norms and from moral norms. I approach this question not from a background in legal philosophy but from the theory of social action. The idea of the paper is to bring to bear on the topic of legal norms work on the structure of institutions and institutional agency.

In a nutshell, my proposal is that legal norms derive from rules which specify role functions in a legal system. Legal rules attach to agents in virtue of their status within the system in which the rules operate. The point of legal rules or a legal system is to solve to large scale coordination problems, specifically the problem of organizing social and economic life among a group of people and their successors. This is not to say that every legal rule pertains to a coordination problem. The legal requirement that one drive on the left in the direction of travel solves a coordination problem for drivers. However, speed limits and laws requiring wearing safety belts while driving do not solve coordination problems but rather have safety as their goal.

The framework for thinking about legal norms that I describe is a framework for thinking about institutions and policies more generally. The idea is to show that legal norms are a

\footnotetext{
1 I take norms in general to be expressed using 'ought' or 'should' statements and to be (intended to be) action guiding. There are norms of etiquette, practical norms, moral norms, and legal norms among others. Rights are correlative to duties: if one has a right to autonomy, others have a duty to (and so ought to) respect it. Legal rules or laws generate legal norms. Some ascribe powers or give permissions or set limits. These are normative rules with implications for how others ought to legally act with respect to those given powers or permissions, but I am not counting them as norms per se since they are not specifications of what one ought to or should do or not do legally.
} 
species of institutional norm. There are two central ideas. The first is the idea of a role in an institution. The second is the idea of proxy agency. Proxy agency involves one agent or group acting under the authorization of another agent or group (perhaps subsuming it) in a way that makes the actions of the proxy count as actions (under a description) of the individual or group for which it is a proxy. We get the characteristic structure of a legal system by conceiving of an institutional group, itself conceived of as a set of interlocking roles realized in individuals, as having one or more roles for proxy agents who are authorized by the group to make policy for the group. The set of rules governing the basic constitution of the group and spelling out the powers of the policy proxies determine fundamental norms for the group with specific role responsibilities attaching to particular positions in institutional arrangements. The policies determine further norms whose force derives from the fundamental norms. We must then say some further things to distinguish institutions and policies which we wish to designate as legal.

In section 2, I introduce the conceptual machinery of constitutive rule, status function, status role, collective acceptance, substantive and formal acceptance, rights and duties associated with status roles, and proxy agency. ${ }^{2}$ In section 3, I apply the framework to the explanation of legal norms, compare the account to the social practice theory and Shapiro's planning theory, explain its bearing on the debate between legal positivists and natural law theorists, explain what it tells us about the sort of authority laws have over its subjects, discuss the role of enforcement, Hart's (1961) distinction between primary and secondary rules, and a puzzle about laws that seem regulative rather than constitutive. In section 4, I sketch a preliminary and tentative answer to the question in what way a legal system differs from other institutions with a similar structure. Section 5 is a brief conclusion.

The upshot is that legal norms are socially constructed in a precise sense.

\section{Conceptual foundations of institutional reality}

Institutions come in (at least) two varieties. First, there are institutions as stable transferrable jointly intentional practices. Language and systems of bartering are institutions in this sense. Second, there are institutions in the sense of a set of transferrable roles inter-defined in terms of their functions established to collectivize behavior for one or another purpose. Clubs, teams, universities, corporations, general partnerships, city governments, and nation states are institutions in this sense. I am primarily concerned with institutions in the second sense and will henceforth use 'institution' in this sense.

Institutional roles are status roles. Institutional membership is itself a status role. Being university professor or student, a member of a club or the parliament, are status roles. A status role is a variety of status function. A status function is a function that an object has in an essentially intentional social transaction that it can perform only by its being collectively accepted, in a certain sense, that it has that function. Searle introduced the notion in his 1995 book The Construction of Social Reality in the following passage:

2 These ideas are developed in further detail in (Ludwig 2014, 2017a). 
The radical movement that gets us from such simple social facts as that we are sitting on a bench together or having a fistfight to such institutional facts as money, property, and marriage is the collective imposition of function on entities, which-unlike levers, benches, and cars - cannot perform the functions solely by virtue of their physical structure. ... The key element in the move from the collective imposition of function to the creation of institutional facts is the imposition of a collectively recognized status to which a function is attached. Since this is a special category of agentive functions, I will label these status functions. (Searle 1995, p. 41)

Being a 10 pound note, a pawn or knight in chess, a crown, an official seal, a driver's license or passport, are all status functions. The curious thing about status functions is the requirement that they be collectively accepted as having a function in order for them to be able to perform it. This contrasts with other agentive functions (functions defined in terms of the purposes of agents) like a two man cross-cut saw. While a two man cross-cut saw can be used intentionally for its purpose only if it is recognized as a two man cross-cut saw, its function can be performed without its being intentionally being used for that purpose. In the woods a blind man may come upon the handle of a two man saw at the same time at which another blind man comes up the other handle, while it is set against a tree. One pulls experimentally, the other pulls back, and soon they have felled a mighty oak, without realizing that they are doing so. But a ten pound note cannot be used for its function unless it is accepted as a certain unit of monetary exchange by those involved in the transaction. Status roles are the same. No one can function as the CEO of a company unless in the relevant community it is collective accepted (by most at least) that she has that function.

In the following, I explain why status functions have this special feature and what distinguishes status roles among other status functions. The key idea is that the functions in question are defined by constitutive rules which specify a role for something in a social transaction without specifying what is to fulfill the role. This presents those who intend to engage in it with a coordination problem. Solving it requires them to coordinate on the same thing, and, hence, to collectively accept it as playing the role, or having the function. Next, I will explain how norms associated with institutions arise from the definitions of the status roles that people occupy. I will explain in what sense the notions of rights and duties arise in connection with those functions-why this talk is apt. This will show that these notions of rights and duties are entirely socially constructed. This doesn't mean that they have no force, and it does not mean that they are not shaped by other non-socially constructed norms and values, but it does mean that in their nature they are entirely the product of human intentional activity and have no status or force or authority beyond what we give them. Then I will argue that this applies in a straightforward way to legal norms which have the same source and status.

\section{Essentially Intentional Activity Types and Constitutive Rules}

I begin with the concept of an essentially intentional activity type. These come in two varieties. 
(1) Activities defined in terms of patterns of behavior (individual or collective) that are instantiated intentionally.

(2) Activities defined in terms of a goal intentionally pursued.

Examples of (1) are playing solitaire, shaking hands, having a conversation, playing a game of chess, writing and passing legislation. Examples of (2) are looking for your lost keys, waiting for the Second Coming, and checking your work for mistakes. I am concerned here only with the former.

A simple example is the play of tic-tac-toe (noughts and crosses). The rules of the game describe constraints on a pattern of activity by two people. We can think of all the possible sequences of moves in a two player game constrained by the rules as defining a type of activity pattern. From the rules we can extract a description of the pattern. The description involves roles for two agents. The pattern can be instantiated in principle accidentally. In this case, it is not an instance of tic-tac-toe. For it to be tic-tac-toe, the rules must be followed jointly intentionally, with the agents playing agreeing on who has what role (this is part of the pattern that they intend to instantiate). In addition each agent must intend to win, where the winner is the one whose mark occupies three contiguous squares (including diagonals) in a three-bythree grid. The description of the activity pattern in terms of the alternating actions of the two agents engaged in it become rules for the activity when they are treated by them as guiding their behavior. Since playing tic-tac-toe requires that the pattern be instantiated intentionally by the agents, following the rules jointly intentionally suffices for playing tic-tac-toe.

A constitutive rule is a rule the (intentional) following of which brings into existence the type of activity it governs, whereas a regulative rule is one the following of which brings order into an activity type that can exist without the rule being followed, e.g., Robert's Rules of Order (RRO). ${ }^{3}$ Thus, we have an explanation of the status of constitutive rules for activity types. Constitutive rules are descriptions of activity patterns taken as a guide to behavior in relation to an activity type that requires that the activity pattern be instantiated intentionally (or jointly intentionally). Constitutive rules are not a special type of rule. They are only special in relation to an activity type whose concept requires not just that the activity described neutrally with respect to whether it is produced intentionally, but also that it be intentionally instantiated. If this is right, then for every rule defining an activity pattern, there ought to be an activity type relative to which it is a constitutive rule. And this is clearly the case. Define a parliamentary meeting as one conducted in accordance with RRO. Then RRO are constitutive of parliamentary meetings. A consequence is that constitutive rules govern essentially intentional activity patterns.

\section{Status Functions}

What is the relevance of this to status functions? Shift the example to tournament chess. There are six types of pieces in chess. The number of each type and their initial positions on a

\footnotetext{
3 The concept of a constitutive rule can be found in Kant and Wittgenstein. It has been developed in one form or another by (Rawls 1955; Anscombe 1958; Hart 1961; Searle 1964, 1969, 1995, 2005), among others.
} 
board are specified by the rules. How each can then be moved is specified by the rules with the white player taking the first turn, followed by the black player, and so on, until one of the end conditions for the game is reached. The rules determine a pattern of activity involving the pieces. But what things in the world are pawns, knights, rooks, bishops, kings and queens? The rules don't tell us. What they give us are functional role concepts. What role a pawn, etc., is to play in the game. Thus, the constitutive rules for chess specify functions for items in a social transaction without telling us what things are to play the roles.

This presents two people who want to play chess with a coordination problem. To play chess, they have to settle together on what things are to play the roles specified by the rules. Of course there are standard chess sets. But anything will do. You can play chess with bottle caps and a checkered picnic tablecloth on a train trip as long as you and your opponent agree on what's what. Thus, in a sense, they have to collectively accept that these things are the pawns (black and white), the knights, and so on.

What is collective acceptance? Is it belief? Belief will typically be involved, but what is fundamentally required is that, in chess, e.g., the players' intentions directed at their playing chess together involve the same items in the same roles. Following the literature, I will call the intentions individuals have when they are participating in joint intentional action we-intentions. I do not mean by this to suggest that this involves a special mode of intending (cf. (Searle 1990, Gilbert 2009). My view (Ludwig 2016) is that what distinguishes we-intentions from I-intentions is their content, and that the concepts involved are already in play in our understanding of individual intentional action (see (Bratman 2014) for another reductive view and (Tuomela $2005,2013)$ for a view on which the content of we-intentions contain irreducible concept of shared intentional agency). What is special about on my view is the particular structure of the content. A taxonomy of views is given in Figure 1. 


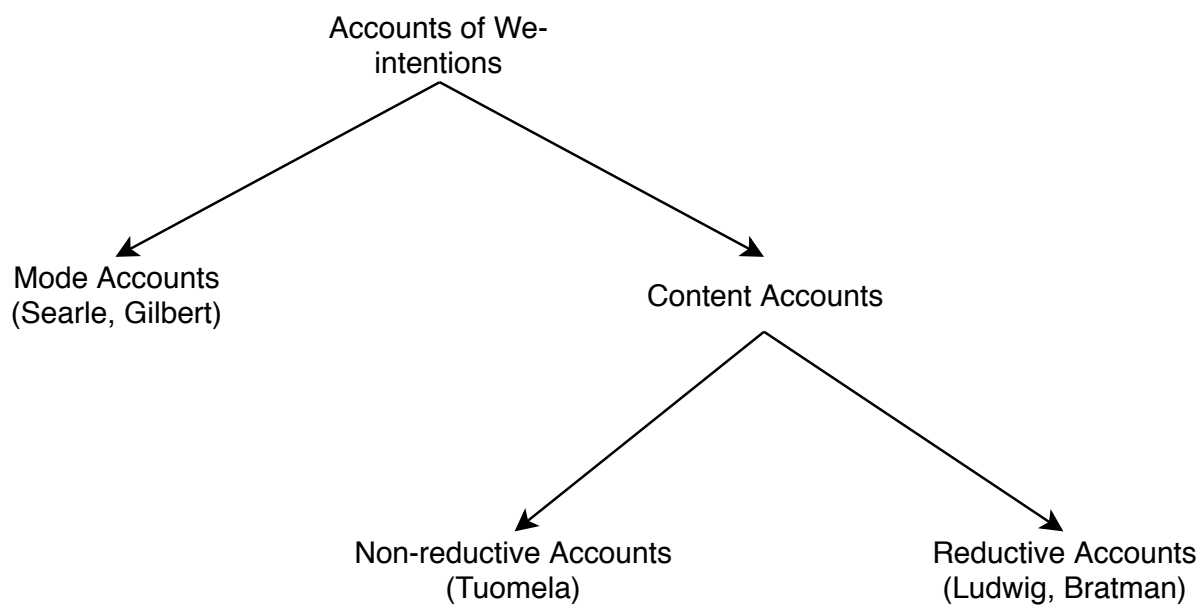

Figure 1: Types of Accounts of We-intentions.

For our purposes it won't matter what the analysis is, though it does matter that we take shared intention, for example, our shared intention play chess, to be a matter of each of us weintending to play chess, that is, we treat shared intention as a distribution of individual intentions with appropriately interlocking contents (and a special mode as well on some views). So collective acceptance of something as having a certain function, specified by constitutive rules for an activity type that do not specify what is to serve the function, is a matter of the members of the group having we-intentions directed at the same objects in the same roles with respect to the activity. This is what it is to impose a status function on an object. This does not have to be a reflective exercise, and for types of activities which we are familiar with we may just fall naturally into a salient coordination without discussing it or thinking much about it.

If we play chess with bottle caps and a checkered tablecloth one off, then what matters is just that we direct our we-intentions at the same tokens we press into service in various roles. Often, we want to settle on the same things, or more broadly things of a certain type, as playing the roles, anticipating an open-ended number of occasions on which we might wish to play chess (and so for other such activities). In this case, we have generalized conditional weintentions to play with the particular items in the roles or with types of items in the roles whenever we engage in the relevant type of social transaction. These generalized conditional we-intentions sustain a convention with respect to the use of the items or types of items. Thus, standing status functions for particulars or types are sustained by conventions in the relevant community. These are practices that are stable, social, arbitrary, and reciprocal and they meet the Lewisian standard of solving coordination problems (Lewis 1986). 


\section{Status Roles}

Status roles are a particular type of status functions. They are distinguished from status functions generally in being (a) status functions assigned to agents who (b) are to exercise their agency in fulfilling at least some of the functions of the role. Examples are being a university professor, senator, member of the House of Lords, Supreme Court justice, club president, Prime Minister, grocery store clerk, student, criminal defendant, attorney, barrister, judge, prisoner of war, enemy combatant, and so on. Status roles can be assigned to groups as well as individuals: the Supreme Court, the Parliament, the Intergovernmental Committee on Climate Change, a member of the United Nations, and so on. The functions assigned to groups however are carried out by its members (or enough of them doing it well enough) carrying out theirs.

What status roles have in common is that in the relevant community it is collectively accepted that those possessing them are

(i) to give or accept directions or permissions to or from others, given their status roles, or

(ii) to play certain roles or do certain things in joint activities or types of social transactions (see below for a further specification of the range of things),

(a) on certain conditions obtaining or

(b) at their discretion or

(c) upon the exercise of their judgment about certain matters which all parties to the arrangements are to act in conformity with, in accordance with their own status roles.

As for status functions in general, status roles are possessed by agents by virtue their being collective accepted as having those roles, where this is a matter of enough members of the relevant community having appropriate generalized we-intentions with respect to action plans involving interacting with the agent with the role.

We can call a role that involves directing others in virtue of their roles a command role (a general in the army, a manager in a firm), and a role that involves taking direction from others (a private, an employee), in virtue of the role, a compliance role. Status roles may and often do combine both of these elements, but need not involve either.

The powers that agents may have in virtue of their status roles include

(i) directing or

(ii) giving permissions to others,

(iii) exercising rights,

(iv) making findings that have an official status that others must conform their behavior to,

(v) issuing rules (which are generalized directives), and

(vi) conferring status roles on others or status functions on things. 
These are real powers. They effect constitutive changes to the fabric of social reality. They make a difference to the causal evolution of the world. But they reside entirely in the collective acceptance of the relevant community that those with those roles have those powers. Thus, they supervene on the conditional we-intentions of members of the relevant communities. It comes to this: when we confer on someone a status role that involves the exercise of a power, we are committed to engage as appropriate in collective intentional behavior in which that person plays the relevant role. A simple example is one person committing himself to following another's directions. This confers a power on the other, but it resides entirely in his willingness to follow through on his commitment and the other to accept the arrangement. The same goes for the fully articulated interlocking roles and institutions of modern life. The practical difference lies in the individual having very little ability to affect the basic structure of social reality by withdrawing acceptance of large-scale institutional arrangements because of how many others would have to cooperate.

We can distinguish between two basic types of status roles. The first sort I will call agent status roles. Agent status roles presuppose that the person to whom they are assigned is party to the collective acceptance that imposes the role on her. The second sort, which I will call subject status roles, ${ }^{4}$ in contrast, are assigned to agents independently of whether they accept the role. Being a university professor is an agent status role. Being a prisoner of war or persona non grata are subject status roles. Even functions of subject status roles involve their possessors exercising their agency in those roles in the sense that they are supposed to recognize the roles assigned to them and to recognize that those roles involve behaviors on their part in various circumstances. However, they need not participate in the collective acceptance that assigns them the role (e.g., prisoners of war), and there is no presumption that they will willingly fulfill the role assigned, hence, the need to make provisions for various forms of coercion.

Some status roles have a hybrid character in the sense that they are in certain conditions assigned without the presumption that their assignee is party to the collective acceptance that she has that role but also on the basis of the assignee explicitly accepting the role. Citizenship is a hybrid category in this sense because it is assigned by birth right as well as naturalization, and because until citizens reach their majority, they are not assumed to have fully accepted their roles as citizens (and the associated rights and responsibilities). It is important for our discussion though that when citizens reach the age of majority, they are presumed to be party to the collective acceptance in accordance with which they are citizens. ${ }^{5}$

\footnotetext{
4 In previous work I have called these "patient status roles" after the distinction in linguistics between the thematic (or case) roles of agent and patient (actor and thing acted upon). In the context of this discussion, "subject status role" has the advantage of emphasizing the role of the exercise of power to ensure conformity of behavior to the assigned role.

5 This might be and has been disputed. But it is important for the thesis I want to develop about the authority of the law that this is the default assumption. It is, it seems to me, part of the ideology of citizenship. I will offer a few supporting remarks later, but I will not try to offer a full defense of the assumption in this paper.
} 


\section{Substantive and Formal Acceptance}

Agent status roles are designed for agents who are party to the collective acceptance by which they have the role. They are assumed to be sincerely engaged, when appropriate, in the kinds of joint activities defined in part by someone performing the functions of the role. Having the role may be defined in terms of the agent's being party to the acceptance, so that absent accepting it, the agent does not genuinely have the role.

This may be appropriate for small scale organizations. However, in larger scale organizations which have roles to play in relation to other large organizations, it becomes more important that organizations can rely on someone not to capriciously opt out. For these purposes three innovations are necessary.

The first is that we allow for a distinction between formal and substantive acceptance of a role. Formal acceptance of a role is a public acceptance of the role that represents oneself as committed to fulfilling the role's functions.

The second is provision for the relevant status role to attach to someone in virtue of formal acceptance, with further provisions for when the person can be said no longer to have the role.

The third is provision for incentives to fulfill the duties of the role in the form either or punishments for failure or rewards for fulfillment or a combination of both.

Thus, one may possess a role in an organization by formally accepting it (it being collectively accepted in the community that one thereby has it) without being sincere, though it is presumed that you are party to the collective acceptance by which you assume the role. Then performance in the role, until the formal conditions for discontinuance obtain, is expected, and provision made for what steps to take if performance is inadequate, the type of response calibrated to the degree and dimension along which the performance is inadequate. This is an evolution of the idea of a pure agent status role under pressure from the real-world conditions under which human agents make as if to sign on to them.

\section{Rights and Duties}

The design functions of status roles specify how their possessors are to interact with others in virtue of their assigned status roles. The possibility of a gap between assignment of role and performance provides scope for evaluating the role occupant for adequacy of performance. The gap arises from two sources. First, from the possibility of failures of competence or performance in the role. Second, from the possibility of possessing the role even in the absence of substantive acceptance of it, that is, by virtue of not having commitment to fulfilling the functions associated with the status role (or even having commitments to subverting it). Given the possibility of a gap between function and performance, the design specification serves as a standard of evaluation. This is what provides scope for the use of the language of 
rights, on the one hand, and duties or role responsibilities, on the other, in relation to status roles. A role occupant has rights against others in virtue of their role responsibilities with respect to him in virtue of his status role. He has duties or responsibilities with respect to performance of functions in the role in essentially collective intentional activities with others in virtue of their status roles.

Thus, to touch briefly on the legal sphere, a defendant at a trial, willing or not, has both rights and responsibilities. Their source is the design specification of the various roles he occupies and the roles occupied by those whose actions in those roles constitute the conduct of the trial. The defendant has, e.g., the right to be confronted with the evidence against him and to offer a rebuttal. This right derives from the role responsibilities of prosecutors and judges. The defendant has responsibilities as well, e.g., to be present for the trail, to answer questions truthfully, etc. Of course, given that the nature of a trial is adversarial, provision is made for failure of a defendant to fulfill his responsibilities.

Role responsibilities and rights based on occupancy of a role are not moral responsibilities and duties. First, in the case of subject status roles, e.g., that of POW, it is clear that POWs do not have a moral responsibility to fulfill the role of POW. Second, even in the case of agent status role, the functions assigned may themselves be things which in themselves or in some circumstances are morally proscribed. For example, the official torturer has the duty to extract information from suspects under the threat of torture, but this duty is not a moral duty, but instead violates a moral duty. Similarly, the concentration camp commander fulfils his role responsibilities by committing mass murder, but these are not moral responsibilities, but instead responsibilities whose execution involve the violation of his moral responsibilities. One may have moral responsibilities to fulfil one's role responsibilities. These can arise from two sources. First, from explicitly placing oneself under an obligation by promising or agreeing to perform them. Second, by generating expectations of performance in others by one's accepting the role, where their reliance on one in the event of failure of performance will disadvantage them. Even in these cases, of course, the moral responsibilities will be pro tanto, and they are distinct from the role responsibilities as such, understood, that is, in terms of the standard provided by the design function. Here it is interaction of the circumstances of acceptance of the role with general moral principles which generates a moral responsibility to fulfill the functions of the role. But this is no different from simply giving someone reason to expect performance in a cooperative task in general and then failing to do one's part, or promising or agreeing in general and then failing to fulfill one's promise or to do what one agreed to do.

\section{Proxy Agency}

There is one more concept central to understanding many institutional transactions that needs to be introduced, that of proxy agency. In proxy agency, what one agent or group does counts as another agent or another group, or a subsuming group, doing something. A paradigmatic example is the spokesperson, who in speaking in her role, delivering a sanctioned message, performs an act which counts as her principal's, e.g., announcing something. Other examples 
are the United States declaring war by way of Congress passing a declaration of war, a corporation filing for bankruptcy by way of its lawyers filing papers, a university awarding a degree by way of a clerk in the registrar's office approving paperwork, the legal system sentencing a defendant by way of a judge's doing so.

What is proxy agency? How is it possible for what one person does to count as another person or a group doing something?

The basic idea is that the proxy agent occupies a status role whose function is to signal commitment by a group to act in certain ways. The group counts as an agent of an event of so signaling because the group authorizes the agent by assigning to her the relevant status role (where the agent in these cases is supposed to accept the role as well). So while the proxy performs individual acts, they are of a type that performs a role in a social transaction with others because of the fact that the proxy has been assigned the role.

Take the spokesperson as an example. Focus on the simplest case in which, say, a club is deciding on a method for communicating commitment to various audiences with respect to its official actions. We can imagine the members casting about for a method. They want some public event to be recognized as their making a commitment of a certain sort. It could be that they formulate a message and they all read out one word of it in turn in front of their audience after telling them what the significance of it is supposed to be. But that is awkward and inefficient. A better solution is to convey to the audience that what one member of the group chosen by them says, as a result of being chosen to say it, is to convey that they are committed to acting in accordance with what is said. This is basically the device of the spokesperson, who is authorized speak in the name of the group. This is a status role. What the spokesperson says in that role, e.g., in the assertive mode, conveying a message agreed upon by the group, is both an individual speech act (though not an individual assertion), and a speech act, in an extended sense, by the group, a status function it has in virtue of it being produced by the spokesperson acting in her role. See Figure 2 for an illustration. 


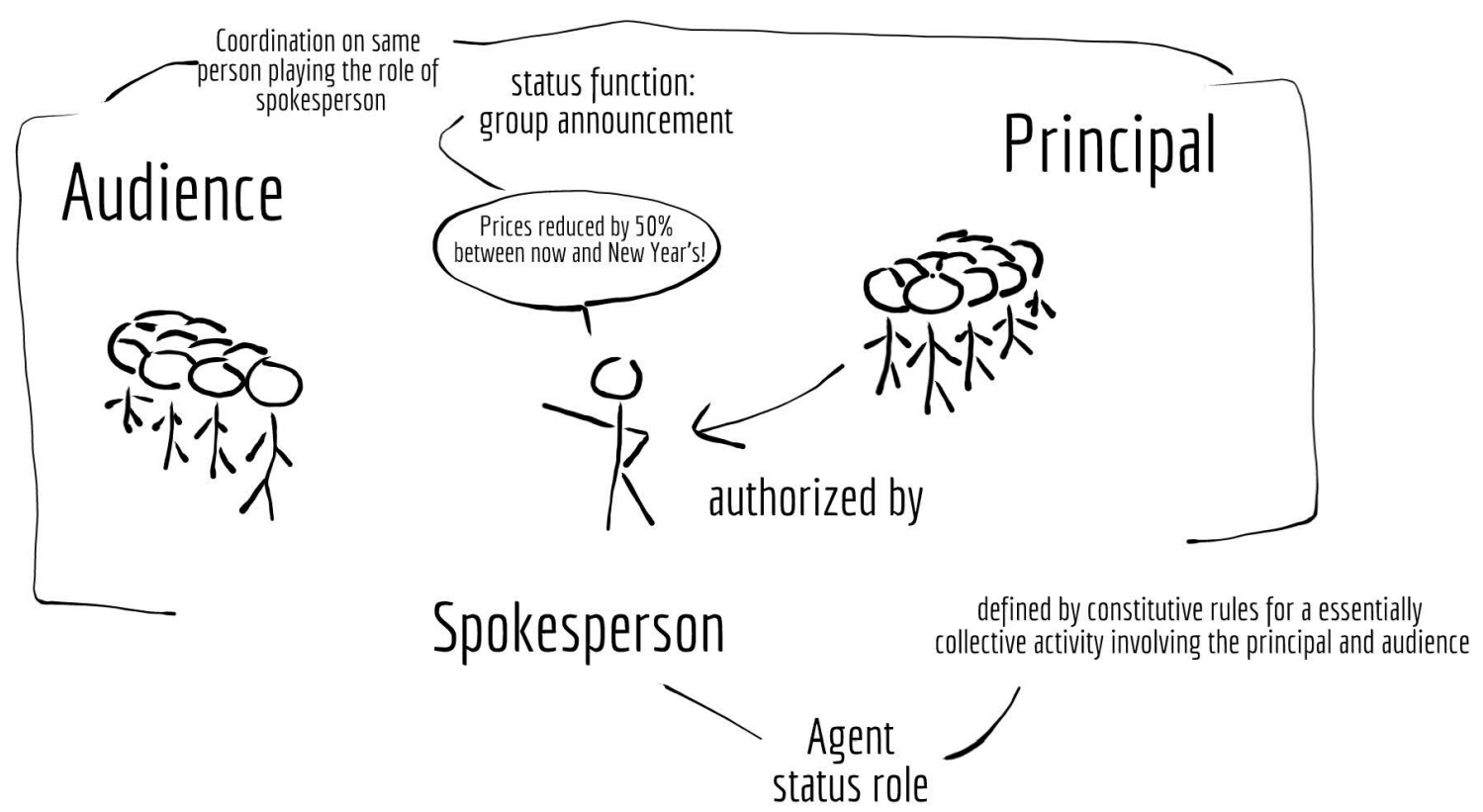

The two keys to understanding proxy agency then are the authorization relation (which is the assignment of the role to the proxy) and the idea of a status role part of whose function involves conferring on something - an event, an object, a process, etc. - by an act of a certain sort in the role, a status function in a social transaction with others (individuals and groups). The community in which the proxy functions includes not just the group that authorizes the proxy but also the consumers of the act, some of whom may be those it is directed on or at, and others indirectly in virtue of the relevance of the status function conferred to their status role functions. ${ }^{6}$

Proxy agents may be assigned many powers to act in the name of the group, including assigning other proxy agents, formulating group policy, issuing orders, interpreting rules, making judgements, undertaking investigations, etc. Authorization is transitive, so the group that authorizes an agent to assign further proxies authorizes those further proxies as well who also act in the name of the group. A group that authorizes proxies to make policy for the group thereby endorses the policies adopted as governing their actions.

Proxy agents are representatives of the groups that authorize them. They act in the name of the group. This is more than just acting in their behalf, which is to act in their interests. For the proxy to act in the name of the group, to be a representative of the group, is to express the agency of the group in her role as a proxy. In many cases, the assignment of proxy roles is itself assigned to someone or some group smaller than the whole group that the proxy represents. The proxy represents the whole group because other members accept the arrangements (which is not to say that they may not work to change them) by which the proxy is assigned. Accepting the arrangements is an indirect form of authorization for whoever acts in the role to

${ }^{6}$ See (Ludwig 2017b) and (Ludwig 2017a, ch. 13) for more on proxy agency; see (Ludwig 2020) for a more detailed discussion of the case of the spokesperson and complications and extensions of the simple case. 
act in their name as a part of the group. Though those whose functions do not give them an explicit role in the assignment do not participate in the formal assignments of the roles, they nonetheless authorize whoever plays the relevant roles to represent them because they sign on to the arrangements. What is crucial for representation is not participation in the formal procedures of assignment but participation in the whole system of roles that sanctions the formal procedures of assignment.

\section{Application to Legal Norms}

\section{Legal Norms are Role Constitutive Norms}

Legal norms apply to those who are in the jurisdiction of a legal system. A legal system is an institution realized in a set of interdefined status roles. Typically a legal system has jurisdiction over a geographic territory and a community largely composed of those who typically live in the territory whose behavior and interactions the laws are designed to govern, though the laws apply them whether they are in the territory or not. These are members of the relevant polis, citizens the case of the laws of a sovereign state. Similarly, the laws apply, typically, to everyone in the territorial jurisdiction whether or not they are members of the polis, e.g., visitors, or transients. The definition of the scope of a legal system is internal to the legal system itself. The maintenance of a legal system is a massive collective intentional activity. The effectiveness of the definitions of the categories of person to whom the law applies relies on there being enough people who collectively accept what the law says about people who fall in these categories for them to function in accordance with the design of the institution. Thus, these are status roles.

In US Law the basic statuses recognized are Alien, US National, US Citizen, Immigrant, Nonimmigrant, Undocumented Alien. Within these categories US law recognized more specific status roles, of course. For example, varieties of visas determine more specific status roles for non-immigrant aliens in US territories. Citizens are subject to Federal Law in the category of citizen (which includes rights not extended to non-citizens). They are typically subject to additional subordinate systems of law at the state, county, township, and city level depending on residence, with rights attaching to state citizenship in addition when further conditions are met, and so on.

Thus, in the general case, being a member of a polis, subject to its legal system, is having a status role. These are hybrid status roles typically. They are conferred often by a birth right, or a right of residence, or in the case of nation states by naturalization, which involves taking an oath. However, though one may be a member of the polis by birthright, upon one's majority one is expect to understand and accept membership. Thus, to focus on citizenship as an example, the status of full citizenship with its rights and duties presumes that the role is 
accepted substantively. Whether or not this is so, one is recognized as having the status, and subject to the norms attaching to it in virtue of the legal regime governing the status. ${ }^{7}$

The status of the norms that arise from being subject to the rules of a legal system as a citizen are no different from those attaching to any status role. To be subject to a legal system is to have a status role. The norms are derived from the design functions of the role. Norms can be conditional or unconditional. A norm is unconditional if it applies in any context. For example, the requirement that one not interfere with the lawful activity of others is unconditional. A norm is conditional if it applies relative to a context or condition. The norms governing contracts apply if one enters into a contract, and more specific legal obligation arise from the details of what is contracted. Typically status roles are layered. In the army, one is a soldier, which is the basic status role. Then one has a rank, which in conjunction with organizational position, determines the chain of command, those from whom one ought to accept directions from when acting in their official roles and those, if any, to whom one has the right and obligation to issue directions acting in one's role, and who in term are required by the design function to accept those directions. Further specifications of the role are determined by one's position in a unit and the functions assigned in joint activities. Citizen is the basic status role in a nation state. Further status roles are determined by residence, employment, licensing, club membership, offices, contracts, calls for jury duty, tickets, arrests warrants, and so on.

An immediate consequence of identifying legal status with having a status role is that this gives one role related rights and duties. These are legal rights and duties, and the norms that arise from these are legal norms and duties. Their ontological status is exactly the same as for rights and duties attached to status roles in general. They exist because there are enough people who collective accept that agents have them for them to function (at least roughly) in the ways they were designed to. In this sense, the roles, and the accompanying rights and duties, are socially constructed. They are socially constructed in exactly the same sense that a pawn is socially constructed, that is, that something is a pawn is determined wholly by the we-intentions and policies (generalized conditional we-intentions) of agents with respect to its function. I will call this the status role account of legal norms.

\section{Brief Remarks on Relations to Practice Theories and Shapiro's Planning Theory}

Among positivist theories, practice theories of one sort or another have been most common. Varieties of these are represented by (Austin 1971, Hart 1961, Hayek 1969). For Austin, it was the habit or custom obedience to a sovereign. Austin's thesis that laws were imperatives issued by a sovereign was famously criticized by Hart. Among other points are that not all laws involve imperatives, for example, laws making provision of marriage or contracts more generally, and it makes the authority of law (to the extent that there would be any) rest on the threat of punishment. Yet Hart also held that legal norms rest on customs, specifically amongst legal

\footnotetext{
7 I am here concerned with norms attaching to official legal status roles. There can be unofficial norms governing practices, including legal practices, in a community governed by a legal system.
} 
officials (and more on this specifically below). Hayek held that legal norms arise from abstraction of rules from customs which then serve as a standard of behavior.

At the heart of the view that I am presenting is the idea that legal norms arise out of specifications of role responsibilities in a legal system. These are sustained by a large scale social practice. But the practice is not a mere custom. It is a large scale joint intentional activity directed at sustaining a system of interlocking institutional roles and realized in both generalized conditional we-intentions and appropriate actions. Customs include such things as eating with knives and forks or with chopsticks, sleeping on mattresses, or on tatami mats, or in hammocks, men wearing pants and women wearing skirts, and so on. Although these kinds of customs are collective (in the sense that they involve a community of agents) they are not essentially jointly intentional. The special character of legal norms does not derive, on the status role theory, from an observed regularity which has given rise to expectations which assume a critical-reflective character, but from the content of the intentions which sustain the systems of roles and associated patterns of joint intentional activity. We act in those role in

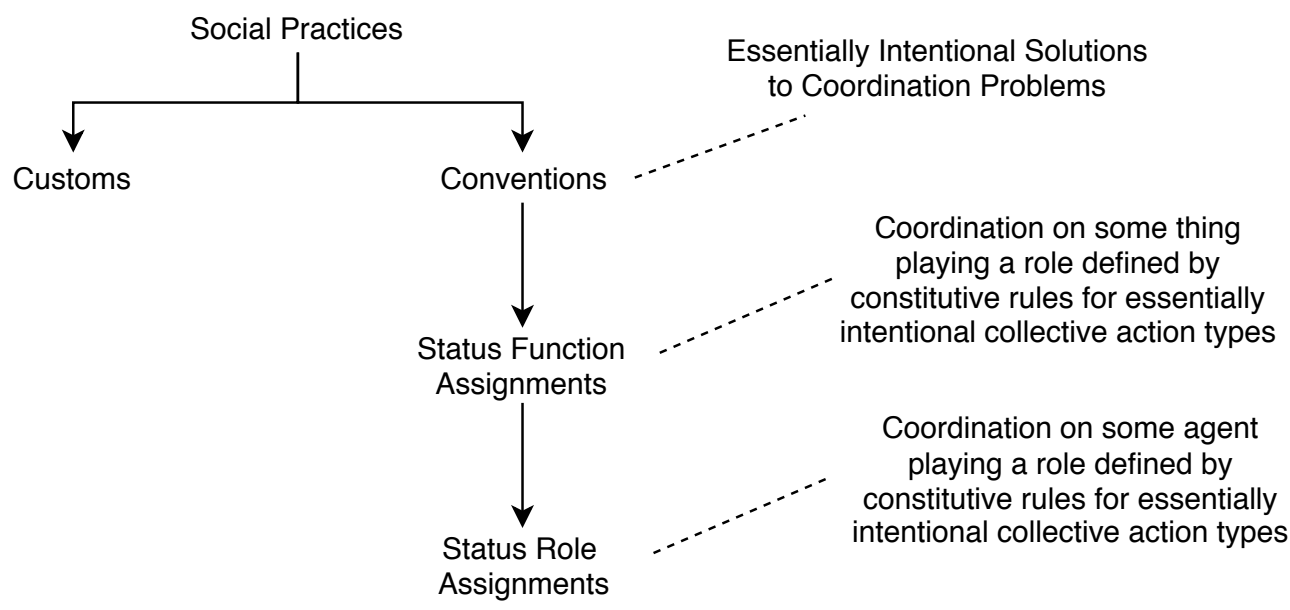

Figure 3: Crucial Distinctions between Customs and Status Role Assignments

accordance with rules that define their functions and thus the patterns of activity generated are generated by participants following constitutive rules for a kind of activity type. Calling this a social practice is not wrong, but it fails to capture essential structure. The relations are illustrated in Figure 3.

Shapiro (2011) has argued for what he calls the planning theory of law. The planning theory is inspired by the work of Michael Bratman on collective action and shared intention. Like the present account, it sees the maintenance of a legal system as a large-scale collective enterprise. "Legal systems are institutions of social planning and their fundamental aim is to compensate for the deficiencies of alternative forms of planning in the circumstances of legality" (Shapiro, 
171). Laws and legal norms are on this view plans, specifically plans regarding the organization of life in a society.

The difference between the planning theory and the status function account lies in the way the latter brings to center stage (i) the idea of a status role as the concept essential to understanding institutional structure, (ii) identifying norms attaching to status roles as arising from their design function, and (iii) identifying legal statuses as status roles. A legal system does embody a plan for the organization of social and economic life. While the specification of actions in an action plan are not per se norms, from an action plan you can extract hypothetical norms, if the plan is the only or the best plan for doing something. If [...] is the only plan you can adopt or the best plan you can adopt for driving to the store, then we can say: if you want to drive to the store, you ought to [...]. If [...] is an action plan for driving to the store, but there are other equally good actions plans for driving to the store (two routes that take the same time, etc.), then all we can say is: If you want to drive to the store, you can [...]. But if there is a range of equally optimal plans, we can say: if you want to drive to the store, then you ought to adopt plan A or plan B or .... These are norms of practical rationality relativized to goals. We could think of legal systems in a similar way. If we want to organize social and economic life, we ought to implement such and such a legal system or some legal system. This leaves out something important, however, about the source and nature of legal norms. If the status role account is correct, the norms attach to status roles. They are not hypothetical in form. They are not norms of practical rationality. They rather fall out of the design specification for the roles. We get to say that someone who has a legal status role ought legally to do something, if that is required by the role, not just if she wants to do it. (This does not mean that that oughtstatement has practical force for her without her being committed to fulfilling the role, but that is why the norms are not just practical norms.) These status roles do play a part in specifying an action plan for implementing a legal system. But the norms are rather like standards for something's being a good knife or a good hammer. Their content is specifiable in terms of a function assigned to the role independently of talking about what anyone wants. This is still essentially connected with human purposes-like tools, status roles have agentive functions. But the standards are at one remove from simple hypothetical norms.

\section{Natural Law Theory and Legal Positivism}

The status role account of legal norms is a version of legal positivism, according to which laws are posited or decided on or defined by social practice-in a word, socially determined, or, as I have been putting it, socially constructed. The law is a social fact that is in principle independent of considerations of its merits or value with respect to other standards of evaluation, and, in particular, moral standards. As John Austin put it:

The existence of law is one thing; its merit and demerit another. Whether it be or be not is one enquiry; whether it be or be not conformable to an assumed standard, is a different enquiry. (Austin 1971, p. 157, first published 1832) 
What is special about the view is the story about the nature of the social construction, that it comes down to the definition and collective acceptance of the imposition of status roles (or the conditions sufficient for having them), and what follows from this about the status, ontology, and authority of the law. We invent legal systems. We sustain them. Their content is up to us. Their norms are standards pertaining to design functions of roles that people accept or have imposed on them. Role responsibilities have to do with what the role occupier is to do qua role occupier. What those responsibilities are, whether of the social worker or concentration camp guard, are internal to the definition of the role. Insofar as this is the case, there is no essential connection with the moral. Reasons we have to act in accordance with the law either derive from our reasons for being party to the collective acceptance by which the system is sustained or from considerations external to their constitutive norms, whether they are prudential (e.g., connected with mechanisms of enforcement) or moral. Legal reasons themselves are not per se motivators or practical reasons in the sense being input ipso facto into practical deliberation.

Is this opposed to Natural Law Theory? It is not opposed to the view that in accepting status roles we acquire moral responsibilities. It does not insist that this is so because the role duties may themselves be proscribed by moral law. But in many circumstances, the application of moral principles to acceptance will generate moral duties connected with the role. It is not opposed to the view that morally we ought to design legal systems to promote moral good, even if not every element of the law is directed toward the moral good. It is not opposed to the view that legal systems in bringing order and stability to social interactions, which is arguable one of their central aims, also thereby promote morally valuable ends. It is not opposed to the view that law may be made that makes reference to moral considerations, even making what is morally wrong be the criterion for what is legally wrong (though this would be fraught with difficulties). It is not opposed to the view that judges may bring to bear moral considerations in adjudicating cases, and even properly so by the lights of the legal system itself. It is opposed to the view that it is intrinsic to the nature of law and legal norms that they involve moral standards. Moral standards are on this view standards external to the law with respect to which the law may be judged, but by moral standards, not standards internal to the law. In sum, though it does not prohibit moral considerations entering into the content and practice of law, the concept of law does not require the deployment of moral concepts in its analysis.

I mention briefly a maneuver one may apply here to set it aside as verbal. That is the idea that by law we mean socially constructed norms of behavior designed as a comprehensive framework for organizing social and economic life backed by force and guided in their formulation by the moral law. This concept of course does include moral considerations constitutively, but it is an entirely verbal maneuver because it consists in adding to a non-moral conception of the law the additional requirement that its formulation be guided by morality. This is equivalent to arguing the physicians are intrinsically moral by adding to the standard conditions for being a physician that one is also morally good. 


\section{Law's Authority}

What is the nature and source of the law's authority on this view? In saying that the law has authority over those to whom it applies I mean that they recognize that they have a reason to obey the law that does not depend merely on the threat of sanction by the mechanisms of enforcement maintained by the legal system if they do not. On the view advanced here, the law has authority in this sense over those who are committed to maintaining the legal system (at least as a whole), that is, those whose conditional we-intentions sustain the status roles in defining the legal system. The authority then is an authority ceded to the law by those who are subject to it. At root it rests on the practical commitment to accept the law and the whole system of status roles in terms of which it is understood. The basic structure is exhibited in Figure 4.

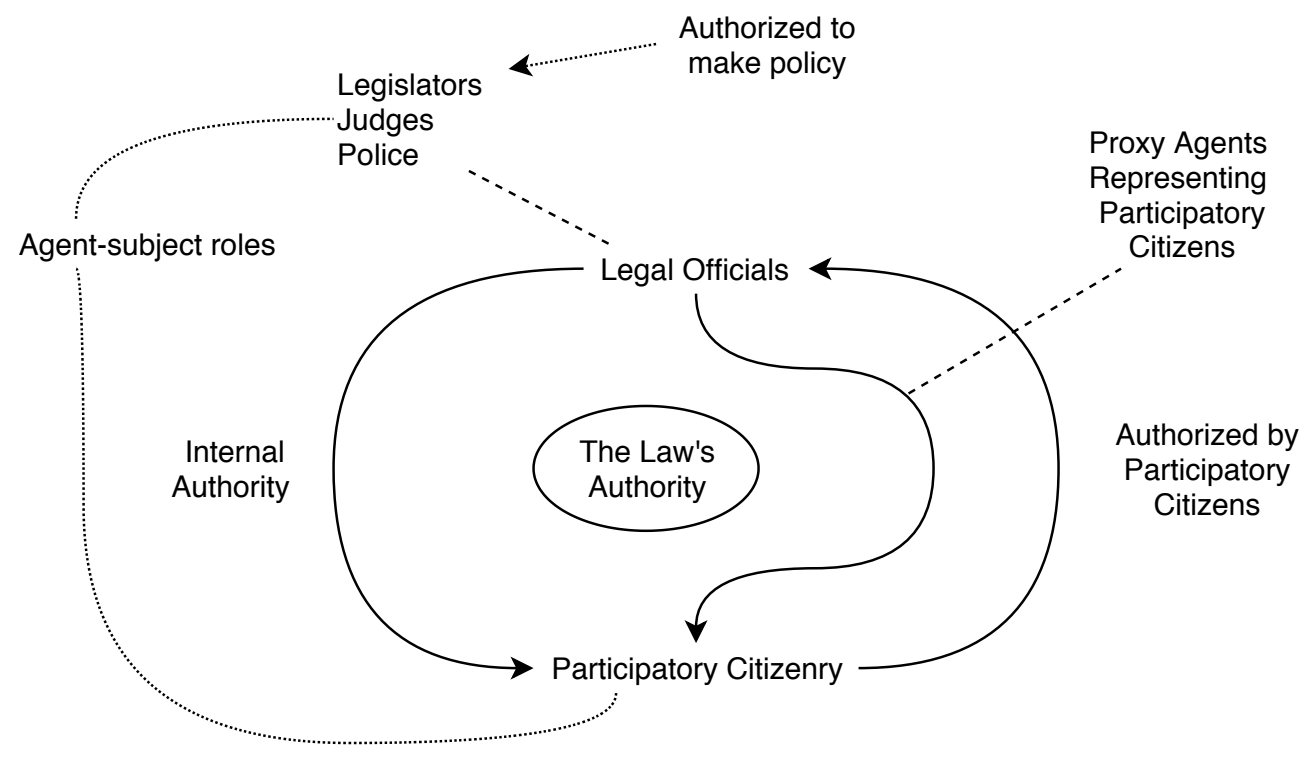

Figure 4: Internal Authority of the Law

Commitment to maintaining the legal system as a whole is consistent with not obeying all the laws all the time (speeding, non-reporting of some income on tax returns) and with civil disobedience. Indeed, civil disobedience, aiming at non-violent change in the law, presupposes a commitment to maintaining the legal system as a whole. In accepting the role of citizen one gives the law its authority over you even when you violate it. This does not mean that you are irrational whenever you violate a law. While it comes with an internal tension, considerations in favor of obeying any given law in virtue of a commitment to the legal system are not overriding.

Not everyone to whom a legal system applies its laws have in this sense ceded authority to the laws. In their case, the law has no authority over them in the sense just articulated. Instead, 
they only have reasons to obey the law that derived from the risk of sanctions if they do not. They are like POWs in this sense. POWs are not POWs by having agreed to be. They obey rules in POW camps because of the threat of sanction if they do not. The authority of the rules imposed on them is given to the enforcers by themselves. It is recognized by them, but not by those on whom they impose the rules.

We can say that:

(1) a rule has internal authority over someone iff the person is committed to its guiding their actions independently of whether they will be subject to sanctions if they follow them;

(2) a rule has definitional authority iff it applies to one by virtue of the assignment of a status function to one when one is not a party to the collective acceptance by which one has it;

(3) a rule has external authority iff it gives one reasons only by virtue of the threat of sanctions if one does not follow it.

POWs are subject to camp rules that have definitional authority over them and external authority over them but no internal authority over them. Definitional authority is thin. It provides external reasons that are not motivators, nor practical reasons. ${ }^{8}$ External authority provides internal reasons in the sense of practical reasons, but nothing that those subject to it recognize as in itself worth pursuing. The difference between POWs and citizens (as ideally conceived) is precisely that for citizens the law has internal authority: they recognize and accept its authority over them independently of the threat of sanctions if they don't conform. ${ }^{9}$

On this view, it is internal to the concept of law that it has internal authority over its target subjects, those for whom it is designed, though it allows for its application without universal acceptance, and that, in any case, for the roles that realize a legal system there must be a significant proportion of those subject to it for whom it has internal authority-who are, I will say, in another sense, its (proper) subjects. This means that where rules govern a subjugated or oppressed people who have only external reasons to obey them, while the rules may have the status of laws in the ruling group, those subject to them against their will are not properly its subjects. This is so even if they are called 'citizens', for they are in name only, and in fact have a status akin to prisoners (though prisoner is not quite the right flavor). De facto they occupy what I called above subject status roles. Thus, a regime may look as if it exercises a legal system that has as its subjects a population, when in fact they are not its subjects at all but only subject to it. It extends a façade of legality over its operations in pretense of a legitimacy that it lacks. In a sense, no one in such a system plays their designated roles (the guards, and maybe prisoners too, pretend that the guards are not guards and the prisoners are not prisoners).

\footnotetext{
8 I have in mind external reasons in the sense of (Williams 1979).

${ }_{9}^{9}$ This is, I think, one of the primary reasons we should recognize the concept of full citizenship (assumed upon one's majority) as including the concept of participation in the sense of being party to the collective acceptance by which the legal system defining it is sustained. For this is what distinguishes being a citizen from being something analogous to a prisoner of war on parole.
} 
It follows from this conception of the force and authority of the law that the legal system is not simply an organization of officials, judges, legislators, prosecutors, police, etc., that is, legal officials. They play special institutional roles in the formulation and administration of the law, but they also represent the citizens (or self-conscious citizens) in general. They function as proxy agents for the self-conscious citizenry. Their authority derives from the whole community (or enough of it) for which the legal system is designed collectively accepting (for the most part) the arrangements, which include the arrangements for roles in which special authority is vested to make and change law, to adjudicate cases, to interpret law, and to determine fact and enforce its provisions, including sanctions for breaking the law. On the view of the law on which the legal system is sustained by a special class of officials (the Hartian tradition), the rest of the citizenry are conceived as like POWs, agents assigned a status role by the officials and who are provided external reasons to conform. On that view, the authority of the law with respect to citizens is external authority not internal authority. This is, I submit, a mistake, once we have in view the possibility of proxy agency and see the role of citizen on majority being to participate in the system and accept the laws that define citizenry in its various contexts as responsibilities internal to their roles as citizens. This is not invalidated by the fact that not everyone who is a citizen will be committed or fully committed to the law. This is just a reflection of the possibility of a gap between role defined functions and performance in the role. What is necessary is only that enough people do participate to ensure the continued stable functioning of the relevant institutions. ${ }^{10}$

\section{Enforcement}

Enforcement looms large in our conception of the law and much of the apparatus of the law is concerned with enforcement and adjudication. Enforcement is the result of the intersection of the design of rules that are to be accepted by those subject to them with the real-world conditions in which they are to be applied, in which the rules are to apply to jurisdictions large in both area and population, to self-interested human beings for whom following the law is not always in their immediate or even long term interest, and to successive waves of citizens regardless of whether they officially sign on to the institutions, as well as to agents temporarily in the intended jurisdiction who are not members of the relevant polis. Enforcement itself requires rules governing it, and these are rules that define status roles for those involved in enforcement and adjudication (police, judges, prosecutors, attorneys, etc.), and it is a distinctive feature of all real world legal systems. Nonetheless, it is a mistake to think that enforcement of rules over a population constitutes the essence of law or we could not distinguish ourselves from POWs.

\section{Primary and Secondary Rules}

Hart famously distinguished between primary and secondary rules.

\footnotetext{
${ }^{10}$ What about corrupt or evil regimes or countries that have been conquered and occupied? In these cases the official citizens, if they act in conformity to law only under the threat of punishment, accord the law only external authority, and are in the relevant sense like POWs.
} 
- Primary rules are ordinary laws.

- Secondary rules are rules about rules:

- rules of recognition (what are the criteria for something being a law),

- rules of modification (how to change the law, including the introduction of new law).

- rules of adjudication (how to settle the application of law in particular cases). In Hart's words: "rules of recognition, rules of change, and rules of adjudication" (Hart, 76-77).

On the account sketched here,

these are all rules that define status roles and their relations to one another.

Actual legal systems all have a long and complex history. Some arise out of the explicit adoption of a constitution, but even in those cases there are typically background legal systems or sets of rules within which the writing and adoption of a constitution takes place. If we think abstractly about the origination of a legal system, it is clear that functionally there need to be rules that (i) define basic roles in the system about who makes (additional) rules, and (ii) who decides on their correct application to cases, and (iii) how they are to be enforced (though we can conceive of communities in which buy-in is universal and enforcement unneeded). Rules of recognition and modification have to do with the first set of roles. What counts as law is what rules are (a) agreed upon in the initial framing in the basic institutional roles and (b) rules that are subsequently promulgated by the appropriate authority without being changed or rescinded in the meantime. The distinction between primary and secondary rules is not fully captured by the distinction between rules that define the basic roles in the system in its origin story, for these may also be subsequently revised. The rules in question here are rules defining the relevant network of institutional roles, some of which are role categories which allow for, for example, the expansion of the polis by the inclusion of additional agents in the relevant roles, but some of which are fixed in number (at least at a point in time).

The rules specifying the basic network of status roles are constitutive rules. They say what it is to be engaged in this kind of joint intentional activity. Then there has to be a collective acceptance among those who realize the network of roles (or enough of them) for the network of roles to be realized in a population. Thus, this approach to understanding legal institutions solves the problem of the original authority of law without an infinite regress or appeal to the presupposition of a Basic Norm (Kelsen 1960). We conceptualize a system of roles; we then realize it; it includes provisions for roles whose function is to promulgate additional rules; these rules are further articulations of the role responsibility and rights of those subject to them; their authority derives from the acceptance of most members of the group of the institutional arrangements by which the lawmaker roles are defined and realized.

Hart said that the basic structures were supported by a social custom. As noted above, this is in the ballpark but not quite right. Collective acceptance of a set of status roles that is transmitted 
over time is a sort of social practice. But the method of reproduction is not imitation of a social practice reinforced perhaps by some social benefit as for social customs. It is rather that the roles are institutional roles and are designed to be successively occupied by different agents. The perpetuation of customs is external to their content. The perpetual succession of organizations is internal to their design. This refinement gives us a more articulate account of the grounding of legality.

Hart's rule of recognition is on this account simply an articulation of a constitutive rule for officials and citizens with respect to what defines at any time the responsibilities attaching to various roles in the legal system. The responsibility is to accept as role duties those specified by rules recognized as meeting relevant criteria.

\section{A puzzle about constitutive and regulative rules}

On my account, status roles are defined by constitutive rules. These rules define forms of joint intentional action. They specify functions that agents play in those action types. They don't specify which agents fill the roles. In this lies the possibility of institutions designed for perpetual existence together with rules for when agents occupy the roles. I have said that legal norms arise from the design function of legal status roles. Laws define role responsibilities. Thus, it seems, laws are to be conceived of as constitutive rules. Yet, some laws, it seems, are clearly regulative rules. For example, traffic laws regulate traffic but don't constitute traffic. There would be traffic (and is traffic) even if the traffic laws don't exist or are not obeyed. So how can they be constitutive rules? The answer is that constitutive rules are constitutive relative to certain activity types. In this case, it is the type: legal behavior. It is not the type: traffic. So rules that are regulative relative to one activity type may be constitutive relative to another.

\section{What makes an institution a legal institution?}

I have assimilated legal institutions to other sorts of institutions and argued that legal norms are a species of the norms that attach to any formal status role in virtue of the ever present potential for a gap between performance and role function. But what makes a legal institution a legal institution? Recognizing that this is a large question that many people have had a stab at, I want to hazard a tentatively characterization. As the concept of a legal system is apt to be a family resemblance or prototype concept, what I aim at is the characterization of a prototype in relation to which we evaluate institutions as legal or not. A legal system is (paradigmatically) an institution, $\mathcal{L}$, that

(a) makes provision for

(i) an institution (which may be a group with its own internal structure or an individual in the limit case) as a component of $\mathcal{L}$ that makes rules for a group of agents ("citizens" or "subjects") on the basis of the statuses in the larger institution who themselves invest it with the authority to do so, i.e., as a proxy agent for them; 
(ii) an institution (which may be a group with its own internal structure or an individual in the limit case) as a component of $\mathcal{L}$ that determines the application of the rules in light of the facts and which settles issues of interpretation;

(iii) an institution (which may be a group of agents with its own internal structure or an individual in the limit case) as a component of $\mathcal{L}$ for the enforcement of the rules by the imposition of sanctions where there are certified violations of the rules (optional but typical);

(b) where the rules of $\mathcal{L}$

(i) have authority over every agent in a designated territory

(ii) have authority over all who are who meet certain conditions such as being born in the territory or born to parents who are subject to the authority of the rules, meeting residency requirements, etc.

(iii) some significant number of whom are party to the collective acceptance by which $\mathcal{L}$ is realized

AND

(iv) take priority over rules and policies issued by other institutions within the territory OR

(v) are recognized by a legal system $\mathcal{L}^{+}$, whose authority is recognized by $\mathcal{L}$, that governs a territory that subsumes $\mathcal{L} s$ territory as taking priority over all other rules and policies issued by other institutions within the territory excepting those of $\mathcal{L}^{+}$ which take priority over those of $\mathcal{L}$.

This is a recursive definition that allows for a hierarchy of legal systems in a territory divided into smaller units within which legal systems operate within the set of rules determined by a system that is not so subject to a subsuming system of rules.

This allows state, county, and city legal systems as genuine though their rules do not take priority over all rules that their territories are subject to in virtue of their authority being recognized ultimately by a sovereign legal system. It rules out church rules (canon law-which is merely operational policy for the church as an institution) which do not attach to a territory and the Mafia with its code which governs only its members (like the rules of a club) and not a territory. ${ }^{11}$

11 The recursive characterization offered here is intended to answer a challenge issued by Scott Shapiro that motivates his "Moral Aim Thesis," namely, that 'the fundamental aim of legal activity is to remedy the moral deficiencies of the circumstances of legality" (Shapiro, p. 213), namely, that otherwise we cannot distinguish the law from other institutions of planning like those of a criminal organization. That law has essentially a moral aim would seem to be refuted by the observation that it makes sense for a society of high functioning psychopaths to institute a legal system with robust mechanisms for enforcement, transparency, and checks and balances for practical purposes, for the order which such a system brings into economic and social life that supports self-centered pursuits that would otherwise not be able to flourish. One might say that even such a system solves moral problems, if one regards "questions about ownership, contractual obligations, ... proper levels of taxation, limitations on public power, legitimacy of state coercion" as moral problems, except that it is not regarded by its realizers as have that as its goal. They are not trying to solve moral but practical problems. If I help save a drowning child, I do what is morally right, but my aim need not be to do what is morally right: I may do it expecting a reward, or an accretion to my reputation which I expect to gain an advantage from. 


\section{Conclusion}

Legal norms attach to legal statuses, which are a species of status role. The norms are constitutive rules for the roles. To be governed by the rules is to perform the role as designed. Having the role does not require fulfilling the function. So though the role of citizen on majority is conceived of as an agent status role, the role attaches independently of whether one accepts it or performs its functions perfectly or even passably. It is this gap between role function and performance that gives rise to the use of the language of duties and rights. The norms specify the regulative ideal. The norms are socially constructed in this sense. Realizing a set of status roles is something that people do together intentionally. Absent a network of status roles being realized by a set of agents acting together under the conception of the network as instantiating a legal system, there are no legal status roles, and, hence, no legal norms (or none that apply to anyone). Other norms that might attach to occupancy of legal positions are derivative from extra-legal norms and the circumstances of occupying the relevant legal position. The authority of legal norms derives from those subject to them authorizing those who promulgate them to determine and modify status roles that they occupy. The authority rests in the commitment of those canonically subject to them to realize the network of institutions that realize the legal system. They have internal reasons to obey the law. Those whose reasons for conforming to the law consist in fear of sanctions are not properly a part of the group that sustains the institutions. They have only external reasons to obey the law.

In summary, we can list some of the advantages of the status role account of legal norms:

- It grounds the law in large scale collective intentional action vindicating, and giving precise content to, the social fact theory of legal norms and the claim that legal norms are socially constructed

- It exhibits legal institutions as continuous with other institution and explains legal norms in the same way as norms attaching to status roles in general.

- It explains the requirement that laws be general.

- It is flexible enough to encompass as wide a range of rules as may govern, guide, restrict, and promote behavior and the assignments of powers, rights, duties, permissions.

- It explains why law should be written so that it is acceptable to its core subjects, since they are (by design to be) party to the collective acceptance by which legal officials have their roles and in virtue of which they are representatives of the laws core subjects.

- It explains why those subject to the law are not analogous to POWs.

\section{REFERENCES}

Austin, John. 1971. The Provice of Jurisprudence Determined. London: Weidenfeld and Nicolson. Bratman, Michael. 2014. Shared Agency: A Planning Theory of Acting Together. Oxford: Oxford University Press. 
Gilbert, Margaret. 2009. "Shared Intention and Personal Intentions." Philosophical Studies 144 (1):167 - 187.

Hart, H. L. A. 1961. The Concept of Law. Oxford: Clarendon Press. Hayek, Friedrich. 1969. Law, Legislation and Liberty. London: Routldge and Kegan Paul. Kelsen, Hans. 1960. Reine Rechtslehre. Vienna: Deuticke.

Lewis, David. 1986. Convention: A Philosophical Study. Cambridge: Harvard Univ Press. Ludwig, Kirk. 2014. "Proxy Agency in Collective Action." Nous 48 (1) (1).

Ludwig, Kirk. 2016. From Individual to Plural Agency: Collective Action 1. 2 vols. Oxford: Oxford University Press.

Ludwig, Kirk. 2017a. From Plural to Institutional Agency: Collective Action 2. 2 vols. Oxford: Oxford University Press.

Ludwig, Kirk. 2017b. "Proxy Agency." In The Routledge Handbook on Collective Intentionality. New York: Routledge.

Ludwig, Kirk. 2020. "Proxy Assertion." In Oxford Handbook on Assertion, edited by Sanford Goldberg. Oxford: Oxford University Press.

Searle, John. 1995. The Construction of Social Reality. New York: Free Press.

Searle, John R. 1990. " Collective Intentions and Actions." In Intentions in Communication, edited by Philip R. Cohen, Jerry Morgan and Martha E. Pollack, 401-415. Cambridge, Mass.: MIT Press.

Shapiro, Scott. 2011. Legality. Cambridge, Mass.: Harvard University Press.

Tuomela, Raimo. 2005. "We-Intentions Revisited." Philosophical Studies 125:327-369.

Tuomela, Raimo. 2013. Social Ontology: Collective Intentionality and Group Agents. New York, NY: Oxford University Press.

Williams, Bernard. 1979. "Internal and External Reasons." In Rational Action, edited by Ross Harrison, 101-113. Cambridge University Press. 